\title{
When knowledge of a heritable gene mutation comes out of the blue: treatment-focused genetic testing in women newly diagnosed with breast cancer
}

\author{
B Meiser ${ }^{\star, 1,14}$, VF Quinn ${ }^{1,14}$, M Gleeson ${ }^{2}$, J Kirk ${ }^{3,4}$, KM Tucker ${ }^{5}$, B Rahman ${ }^{1}$, C Saunders ${ }^{6}$, KJ Watts ${ }^{1}$, \\ M Peate ${ }^{1,7}$, E Geelhoed ${ }^{8}$, K Barlow-Stewart ${ }^{9}$, M Field ${ }^{10}$, M Harris ${ }^{11}$, YC Antill ${ }^{12}$ and G Mitchell ${ }^{13}$ \\ for the TFGT Collaborative Group ${ }^{15}$
}

Selection of women for treatment-focused genetic testing (TFGT) following a new diagnosis of breast cancer is changing. Increasingly a patient's age and tumour characteristics rather than only their family history are driving access to TFGT, but little is known about the impact of receiving carrier-positive results in individuals with no family history of cancer. This study assesses the role of knowledge of a family history of cancer on psychosocial adjustment to TFGT in both women with and without mutation carrier-positive results. In-depth semistructured interviews were conducted with 20 women who had undergone TFGT, and who had been purposively sampled to represent women both family history and carrier status, and subjected to a rigorous qualitative analysis. It was found that mutation carriers without a family history reported difficulties in making surgical decisions quickly, while in carriers with a family history, a decision regarding surgery, electing for bilateral mastectomy (BM), had often already been made before receipt of their result. Long-term adjustment to a mutation-positive result was hindered by a sense of isolation not only by those without a family history but also those with a family history who lacked an affected relative with whom they could identify. Women with a family history who had no mutation identified and who had not elected BM reported a lack of closure following TFGT. These findings indicate support deficits hindering adjustment to positive TFGT results for women with and without a family history, particularly in regard to immediate decision-making about risk-reducing surgery. European Journal of Human Genetics (2016) 24, 1517-1523; doi:10.1038/ejhg.2016.69; published online 22 June 2016

\section{INTRODUCTION}

Traditionally, women with a new diagnosis of breast cancer together with a strong family history of breast/ovarian cancer are referred to a family cancer clinic for genetic counselling and, if appropriate, genetic testing for germline mutations in the breast cancer susceptibility genes BRCA1 and BRCA2 (hereafter BRCA1/2) following completion of surgery and adjuvant chemo- and/or radiotherapy. ${ }^{1,2}$ Now, there is increasing evidence that mutation status may influence breast cancer surgical decisions, in particular decisions between breast conservation and bilateral mastectomy (BM). Many confirmed BRCA1/2 mutation carriers consider more radical surgery, given the high risks of an ipsilateral new breast primary ${ }^{3}$ and contralateral second breast primary cancers. ${ }^{4}$ Furthermore, risk-reducing bilateral salpingo-oophorectomy is recommended to reduce ovarian and tubal cancer risk, and it may also have additional therapeutic benefits for reducing breast cancer risks if the woman is premenopausal at the time of diagnosis. Considerable benefit may therefore be derived from early referral of the newly diagnosed breast cancer patient for genetic assessment. In the future, genetic testing may also direct systemic therapies. ${ }^{5-7}$
Therefore, genetic counselling and testing is increasingly offered shortly after diagnosis to inform breast cancer management, and it is therefore also referred to as treatment-focused genetic testing (TFGT).

Given advances in genetic testing technology (panel testing and the decreasing costs of BRCA1/2 testing) mutation analysis in women newly diagnosed with breast cancer is set to move from highly specialised familial cancer clinics to the mainstream oncology treatment setting. ${ }^{8,9}$ Currently an increasing number of patients with newly diagnosed breast cancer are offered TFGT if they have either a strong family history or other personal and/or tumour characteristics that indicate an increased risk of a BRCA1/2 mutation. These include young age of breast cancer diagnosis, bilateral breast cancer, 'triple negative' breast cancer or membership of ethnicities with founder mutations. ${ }^{8,10,11}$ Marie-Claire King et al ${ }^{12}$ have even suggested that all unaffected women aged 30 and over should be tested. Thus, increasingly women without a strong family history of breast cancer will be identified as mutation carriers.

The psychosocial impact of predictive genetic testing in women with a strong family history is well documented ${ }^{13,14}$ and there is also

\footnotetext{
${ }^{1}$ Prince of Wales Clinical School, University of New South Wales, Sydney, NSW, Australia; ${ }^{2}$ Hunter Family Cancer Service, Waratah, NSW, Australia; ${ }^{3}$ Familial Cancer Service, Westmead Hospital, Westmead, NSW, Australia; ${ }^{4}$ Centre for Cancer Research, The Westmead Institute for Medical Research, University of Sydney, Westmead, NSW, Australia; ${ }^{5}$ Hereditary Cancer Clinic, Department of Medical Oncology, Prince of Wales Hospital, Randwick, NSW, Australia; ${ }^{6}$ School of Surgery, University of Western Australia, Crawley, WA, Australia; ${ }^{7}$ Department of Obstetrics and Oncology, Royal Women's Hospital, University of Melbourne, Melbourne, VIC, Australia; ${ }^{8}$ School of Population Health, University of Western Australia, Crawley, WA, Australia; ${ }^{9}$ Sydney Medical School-Northern, University of Sydney, Sydney, NSW, Australia; ${ }^{10}$ Royal North Shore Hospital, St Leonards, NSW, Australia; ${ }^{11}$ Monash Health, Melbourne, VIC, Australia; ${ }^{12}$ Familial Cancer Centre, Cabrini Health, Melbourne, VIC, Australia; ${ }^{13}$ Familial Cancer Centre, Peter MacCallum Cancer Centre, Melbourne, VIC, Australia

${ }^{*}$ Correspondence: Dr B Meiser, Prince of Wales Clinical School, University of New South Wales, Lowy Cancer Research Building, C25 Level 4, Lowy Cancer Research Centre C25, Sydney, NSW 2052, Australia. E-mail: b.meiser@unsw.edu.au

${ }^{14}$ Joint first authors, these authors contributed equally to this work.

${ }^{15}$ Members of the TFGT Collaborative Group are listed before References.

Received 17 December 2015; revised 12 March 2016; accepted 20 May 2016; published online 22 June 2016
} 
an emerging body of literature on the impact of TFGT. ${ }^{15,16}$ Generally these studies, conducted almost exclusively among women with a family history, found that while distress among carriers increased shortly after receiving results it returned to pretesting levels over time. $^{13-16}$ In women with no, or minimal, knowledge of a family history, a mutation-positive TFGT result is likely to be unexpected. These women may be particularly vulnerable to psychological distress following TFGT. Very few studies are currently available on the psychological impact of TFGT or traditional genetic testing for $B R C A 1 / 2$ mutations in the subgroup of women with no knowledge of/minimal family history (FH), and the available studies are limited to Ashkenazi Jewish people participating in population-based screening. ${ }^{11,17}$ This article describes a qualitative study that compared the impact of TFGT on psychological adjustment and associated unmet support needs in women with no knowledge of/minimal (FH-) and with a strong family history $(\mathrm{FH}+)$.

\section{MATERIALS AND METHODS}

\section{Participants}

Eligible participants were women who participated up to 2 years earlier in a non-inferiority trial, assessing the impact of brief written education materials versus traditional genetic counselling in preparing women for decision-making about TFGT, the methodology of which is described in detail elsewhere. ${ }^{18}$

A separate quantitative analysis, comparing psychological and surgery outcomes in $\mathrm{FH}+$ and $\mathrm{FH}-$ women, was also performed, the results of which will be reported separately. A multi-method design that combines a qualitative with a quantitative design has the advantage of compensating for the deficiencies of one genre with the strengths of the other and allows for modification and strengthening of the findings through triangulation, that is, ascertainment of whether findings from different data sources corroborate or contradict each other. ${ }^{19}$

Eligibility for the original study included women aged between 18 and 49 years at diagnosis; diagnosis of invasive breast cancer amenable to surgery or ductal carcinoma in situ; proficiency in English and either: (i) a strong family history of breast and/or ovarian cancer or (ii) a personal diagnosis of bilateral breast cancer and/or Ashkenazi Jewish ancestry and/or triple negative breast cancer in the absence of a strong family history. Exclusion criteria were mastectomy or radiotherapy for their current cancer, prior genetic counselling and/or testing; diagnosis of distant metastases or lobular carcinoma in situ only. Invitation to the study was via the treating breast surgeon. Women were able to choose whether or not to have TFGT, and testing was provided free of charge.

A letter of invitation for this component of the study together with a participant information pamphlet, consent form and opt-in response sheet was mailed to a purposively selected sample of 42 of the original 128 participants, with 7 women declining to participate and 14 women not responding. One woman withdrew after providing consent as she suffered a relapse of the disease. Purposive sampling ${ }^{20}$ was undertaken, such that four groups of women were included: (i) those offered TFGT based on a strong family history who were found to carry a BRCA1/2 mutation (FH+ Mut+, $n=5$ ); (ii) those with no known or a minimal family history only with an identified mutation (FH - Mut+, $n=5$ ); (iii) those with a strong family history with no mutation identified (FH+ Mut -, $n=5$ ); and (iv) those with no/minimal family history with no mutation identified ( $\mathrm{FH}-\mathrm{Mut}-, n=5$ ). Recruitment was initially undertaken until $N=20$, with the stipulation that if informational redundancy had not been achieved by this point then recruitment would continue.

Women who returned the response sheet and opted in were then contacted by the interviewer (MG) by telephone to arrange a time for the telephone interview. Semistructured interviews lasting 45-60 min were conducted by MG covering: adjustment to breast cancer diagnosis, emotional adjustment to TFGT results and sharing of these results with relatives, impact of TFGT results on surgical decisions, and perceived unmet support needs.

\section{Data analysis}

Interviews were digitally recorded and transcribed verbatim, then coded in NVivo Version 10 by a second researcher (VQ). The qualitative analysis was guided by Miles et al. ${ }^{19}$ These authors describe a range of techniques to produce credible and replicable results in qualitative terms and to guard against analytic bias. ${ }^{19}$ An integrative approach to developing the coding structure was used, incorporating both deductive components based on the interview schedule as well as inductive features as new themes emerged. ${ }^{19}$ The final coding structure was then reviewed by a third researcher (MP). Matrix coding was used to cross-tabulate emergent themes between groups to facilitate comparisons across family history and carrier status. ${ }^{19}$

\section{RESULTS}

Overall 20 women with a mean age of $38.6(\mathrm{SD}=6.6)$ years $(\mathrm{FH}+$ mean $=38.9, \mathrm{SD}=3.7$ and $\mathrm{FH}-$ mean $=40.7, \mathrm{SD}=7.8)$ were interviewed an average of 22 months (range 10-38) since result disclosure. In terms of other demographic characteristics the $\mathrm{FH}+$ and $\mathrm{FH}-$ women were similar, with $8 \mathrm{FH}+$ and $5 \mathrm{FH}$ - women reporting that they had children, $6 \mathrm{FH}+$ and $4 \mathrm{FH}$ - women reporting that they were married or living as married, and $9 \mathrm{FH}+$ and all $10 \mathrm{FH}-$ women reporting that they spoke English at home. In terms of their education, $2 \mathrm{FH}+$ and $5 \mathrm{FH}-$ women had a bachelor degree or higher, $2 \mathrm{FH}+$ and $3 \mathrm{FH}$ - women had vocational or College qualifications, $3 \mathrm{FH}+$ and $2 \mathrm{FH}$ - women had Higher School Certificates and $3 \mathrm{FH}+$ women had School Certificates. All 20 women had invasive carcinoma. Three participants who reported no family history of breast/ovarian cancer at diagnosis subsequently discovered relatives with BRCA1/2-related cancers after TFGT. These women provided an interesting snapshot into their discovery that they were actually part of a bigger, previously inaccessible narrative, and as such their views are discussed separately where relevant.

\section{Adjustment to breast cancer diagnosis}

Table 1 shows sample quotes illustrating themes in relation to adjustment to breast cancer. A family history of breast cancer seemed to be an important factor in a woman's adjustment to the diagnosis. For FH+ women, the predominant feeling seemed to be that although the diagnosis may have been surprising, a sense of inevitability had prepared them for it. $\mathrm{FH}+$ women often framed their own prognosis in terms of the positive or negative outcomes experienced by family members. For two women this meant an increased fear of cancer due to relatives having passed away from the disease, whereas other women looked to survivorship within the family for reassurance.

In contrast, the majority of $\mathrm{FH}$ - women were more likely to have discovered their breast cancers accidentally rather than through screening, and seemed to react to their breast cancer diagnosis with more shock and disbelief.

The family history of women also seemed to have important practical implications in terms of understanding the upcoming treatment process, as those with affected relatives were more prepared for this. However knowing someone with any type of cancer may have aided adjustment, as two women mentioned it was helpful to have friends or relatives going through a diagnosis or treatment of any cancer.

\section{Emotional adjustment to carrier status}

Table 2 shows quotes illustrating themes in relation to emotional adjustment to TFGT results and sharing results with relatives. Typically women mentioned feelings of gratitude for the offer of TFGT; some women were aware they would not have been eligible for TFGT testing outside the trial. The majority of women reported feeling that the 
Table 1 Quotations illustrating themes in relation to adjustment to breast cancer diagnosis

\begin{tabular}{|c|c|c|}
\hline & Women with a strong family history & Women with no/minimal family history \\
\hline Topic & Theme and quotation illustrating theme & Theme and quotation illustrating theme \\
\hline Reaction to breast & A sense of inevitability & Shock and disbelief \\
\hline cancer diagnosis & $\begin{array}{l}\text { 'I mean it was a shock don't get me wrong ... but I think deep down I } \\
\text { always knew that I was- I'd always felt that I was waiting to get cancer, } \\
\text { to a certain extent. ' }[33, \mathrm{FH}+, \text { Mut+, 4] }\end{array}$ & $\begin{array}{l}\text { 'Yeah I think that if somebody else had had it you'd sort of... have it in } \\
\text { the back in your mind that there's a possibility because it's a family } \\
\text { trait... But when there's just nothing and you're the first one... it was } \\
\text { a bit daunting.' [ } 40, \mathrm{FH}-, \text { Mut-, } 12 \text { ] }\end{array}$ \\
\hline
\end{tabular}

Preparedness for practical 'I was aware of what they had been through, so I was sort of aware process of breast cancer of what I was up for and maybe my decisions were a little bit easier.' treatment $[40, \mathrm{FH}+$, Mut+, 14]
'I didn't have a big picture of what it really meant ... I figured I was going to get sick, as in the nausea, and I had no idea about any of the other stuff at all... I didn't have a reference point; I didn't have somebody that I could kind of lean on.' [38, FH-, Mut+, 11]

Reference points

$$
\begin{aligned}
& \text { Framing own prognosis in terms of outcomes experienced by family } \\
& \text { members } \\
& \text { 'Mum will be } 80 \text { in January and she'd survived it twice, so I didn't think } \\
& \text { of it as a death sentence anymore like you would have maybe years } \\
& \text { and years ago' [42, FH+, Mut-, 16]. 'I did catastrophize slightly at the } \\
& \text { beginning because I just felt my sister died of this I'm going to die of } \\
& \text { it' [33, FH+, Mut+, 4] }
\end{aligned}
$$

Abbreviations: $\mathrm{FH}+$, strong family history; $\mathrm{FH}-$, no/minimal family history; Mut+, mutation positive; Mut, no mutation detected.

TGFT process and waiting for their results was no more stressful than everything else that was occurring around the time of diagnosis.

Mutation-positive results. For FH+ individuals, most women reported that receiving a Mut+ result was expected.

For FH - women, surprise and disbelief about their mutation status was more common:

'I think finding out that it was genetic was more of a shock than [the diagnosis]-Oh, I shouldn't say that. The genetic came out of the blue. It was another slap in the face.' [33 years, FH - , Mut+, ID 5]

Only one $\mathrm{FH}$ - woman reported having expected a mutationpositive result, as she had reasoned that because of her age and her triple negative tumour it was likely.

Three FH+ women found that their receipt of Mut+ results enhanced a sense of loss for relatives who had passed away from the disease. One woman who lost her sister and another who had lost her mother were saddened that their relatives had not been able to benefit from this genetic information. Another woman who had initially not connected her mother's ovarian cancer with her own breast cancer also experienced enhanced grief after learning her cancer had a genetic basis.

Similarly to the experience of receiving the initial breast cancer diagnosis, it seems that a family history may have aided acceptance of a positive mutation result. This was referenced both in terms of a lack of surprise, but also interestingly, as a realisation that the women were part of a bigger picture. One woman even mentioned that the positive result enhanced her feelings of connection with her mother, who had died from breast cancer when she was young. This feeling of enhanced familial connections and understanding was true also of women who only discovered that they had relatives with breast cancer after their genetic testing. This was in contrast with women who did not have any family history at all, who were less likely to spontaneously mention positives associated with the enhanced knowledge.

No mutation found result. Mut- FH+ women were much more likely to express surprise at receiving a Mut - result, while $\mathrm{FH}-$ women typically reported feeling relieved about their Mut - result.
It seemed that $\mathrm{FH}-$ women tended to adapt quickly after receiving a Mut - result. This experience was markedly different for women with a family history, who despite being relieved not to carry a BRCA1/2 mutation, knew that their residual risk of developing another cancer remained raised, given their strong family history. This resulted in feelings of a 'lack of closure' about their familial risk.

\section{Sharing results with relatives}

Two FH+ women reported that the increased burden of acting as a 'surrogate genetic counsellor' for the rest of their family was difficult. Support from their close relatives during this time also seemed important, with two women reporting that the parent from the affected lineage took on the responsibility of sharing results with more distant relatives.

Although the process of sharing results seemed more difficult for $\mathrm{FH}$ - women, only two participants in the study reported being hesitant to share their Mut+ results. Both women reported fearing negative repercussions from informing their relatives. $\mathrm{FH}-$ participants also mentioned feelings of guilt, often related to the perception they had caused emotional upheaval for their family. Generally the sharing of a 'no mutation identified result' was much more likely to be viewed positively and was commonly reported as being perceived as a relief by relatives.

\section{Use of TFGT results for surgery decisions}

Table 3 shows quotes illustrating themes about using TFGT results to make surgery decisions.

Mutation-positive results. All Mut+ women had BM. It seemed that for $\mathrm{FH}+$ women, the decision to move forward was straightforward; relating back to increased expectations that they would receive a Mut+ result as well as a greater awareness of the surgical procedure due to their prior familial exposure. For three $\mathrm{FH}+$ women, it was clear to them from the outset that they wanted BM, with two women suggesting that a Mut+ result was as much to convince their surgeons to perform the surgery as it was to facilitate their own decisions. One FH+ woman actually deferred receiving her results until after recovery from BM surgery so that she would be more prepared to convey what she expected to be a positive result to her daughters. In 
contrast to this, $\mathrm{FH}$ - women appeared to have a more difficult time making surgical decisions in the required therapeutic time frame.

No mutation found result. Of the FH+ Mut - women, one woman had BM and four had breast conservation. Of the $\mathrm{FH}-$ women, one woman had already had BM before she received the results, two conserved their breasts, and one had breast conservation at the time of diagnosis and then BM after a cancer recurrence. It appeared that for $\mathrm{FH}-$ women, the ensuing decisions were quite straightforward, and three women expressed relief that they did not need a BM. By contrast, $\mathrm{FH}+$ Mut - women were aware that they remained at an elevated risk given they

Table 2 Quotations illustrating themes in relation to emotionally adjusting to TFGT results and sharing results with relatives

\begin{tabular}{|c|c|c|}
\hline & Women with a strong family history & Women with no/minimal family history \\
\hline Topic & Theme and quotation illustrating theme & Theme and quotation illustrating theme \\
\hline \multirow{5}{*}{$\begin{array}{l}\text { Emotional adjustment: } \\
\text { Mut+ result }\end{array}$} & Result was expected & Result was a surprise and shock \\
\hline & $\begin{array}{l}\text { 'I think you could've knocked me over with a feather if it had have come } \\
\text { back negative.' [37, } \mathrm{FH}+, \mathrm{Mut}+, 8]\end{array}$ & $\begin{array}{l}\text { 'I think finding out that it was genetic was more of a shock than [the } \\
\text { diagnosis]-Oh, I shouldn't say that. The genetic came out of the blue. It } \\
\text { was another slap in the face.' [33, FH-, Mut+, 5] }\end{array}$ \\
\hline & $\begin{array}{l}\text { Being part of a bigger picture } \\
\text { 'It was something that I was never ever going to be able to control ... I } \\
\text { thought of it as just a tool to be able to help my sister and the females in } \\
\text { my family' }[40, \mathrm{FH}+\text {, Mut+, 15] }\end{array}$ & $\begin{array}{l}\text { Being part of a bigger picture } \\
\text { 'It's starting to make a little bit more sense to our family now that we've } \\
\text { got the bigger picture... you feel like you fit into something that isn't } \\
\text { random, it hasn't just happened.' [38, FH -, Mut+, 11, who discovered } \\
\text { only after genetic testing that she had other family members with the } \\
\text { disease]. }\end{array}$ \\
\hline & Reactive grief & Increased family awareness \\
\hline & $\begin{array}{l}\text { 'A big part of me was taken away when I lost my mother and I feel like } \\
\text { another part of me has been taken away through all of this. Everyone thinks } \\
\text { you should be thankful that you're still alive, and I guess I should but I - } \\
\text { there's still a big part of me that is having a hard time' [37, FH?, Mut+, C] }\end{array}$ & $\begin{array}{l}\text { 'So that rather than just waiting to see whether or not, you know, they are } \\
\text { going to get cancer we can be more proactive about it and we have the } \\
\text { heads up about it as well.' [38, FH-, Mut+, 11] }\end{array}$ \\
\hline Emotional adjustment: & Lack of closure & Relief and alleviation of worry \\
\hline Mut- & $\begin{array}{l}\text { 'I thought okay you know is there another gene out there that, that either } \\
\text { has not been identified or ... I sort of never got that clarification, that } \\
\text { closure, yeah.' [47, FH+, Mut-, 17] }\end{array}$ & $\begin{array}{l}\text { 'It wasn't something that my kids would have to worry about necessarily } \\
\text { inheriting from me and my sisters as well you know that was the main thing } \\
\text {... there's that small you know glimmer of hope' }[40, \mathrm{FH}-, \text { Mut - , 13] }\end{array}$ \\
\hline Sharing results with & Acting as a surrogate genetic counsellor & Fear of negative repercussions and guilt \\
\hline relatives & $\begin{array}{l}\text { 'I just, I wasn’t sure how I was going to cope with having to support [my } \\
\text { sister] while I was trying to deal with it myself.' [37, FH+, Mut+, 8] }\end{array}$ & $\begin{array}{l}\text { 'I was very closed about it...So I was petrified she [sister-in-law] was } \\
\text { going to blame me that her children might have this genetic thing, which } \\
\text { was out of my control.' [33, FH-, Mut+, 5] 'I didn't feel like it was my } \\
\text { fault, but I kind of felt responsible that everybody knew this and, and it } \\
\text { was kind of my fault that they knew' [28, FH -, Mut+, 2] }\end{array}$ \\
\hline
\end{tabular}

Abbreviations: $\mathrm{FH}+$, strong family history; $\mathrm{FH}-$, no/minimal family history; Mut+, mutation positive; Mut-, no mutation detected.

\section{Table 3 Quotations illustrating themes in relation to TFGT to facilitate surgery decisions}

\begin{tabular}{|c|c|c|}
\hline & Women with a strong family history & Women with no/minimal family history \\
\hline Topic & Theme and quotation illustrating theme & Theme and quotation illustrating theme \\
\hline Surgery decisions: & Decision-making about BM straightforward & Decision-making about BM difficult \\
\hline Mut+ & $\begin{array}{l}\text { 'I'd already made the decision essentially that if the results were positive I } \\
\text { was going to have a double mastectomy... Yeah it wasn't a very hard thing } \\
\text { to deal with to be honest.' [37, FH+, Mut+, 8] 'It didn't change my mind } \\
\text { but it obviously helped change my surgeon's mind who said 'yeah absolutely } \\
\text { we will take them both off for you' a no-brainer so that was quite good. So it } \\
\text { was good that we all agreed.' [33, FH+, Mut+, 4] }\end{array}$ & $\begin{array}{l}\text { 'I said, 'No, won't even talk about mastectomy, I'm too young,' ... I hadn't } \\
\text { even - still that double mastectomy was quite shocking to me I have to say.' } \\
\text { [33, FH -, Mut+, 5] } \\
\text { 'Especially all in that time frame as well just to sort of you know say good } \\
\text { bye to them as well and to deal with it and just be like no you've got to go. } \\
\text { You know, I don't want to ever go through this again.' [25, FH -, Mut+, 1] }\end{array}$ \\
\hline Surgery decisions: & Struggling with ambiguity of a Mut- result & Relief at not having to undergo $B M$ \\
\hline Mut - & $\begin{array}{l}\text { 'Basically the feedback I got, it's all statistics and that's all you have to go } \\
\text { by ... You sensed a feeling [from surgeons]...there was never a suggestion } \\
\text { or a push, it was all about what decision I needed to make for myself. } \\
{[38, \mathrm{FH}+\text {, Mut }-, 10]}\end{array}$ & $\begin{array}{l}\text { 'Relief because I didn't have to make a decision to have a mastectomy or } \\
\text { not ... that's one less thing I have to worry about.' [40, FH -, Mut - ] }\end{array}$ \\
\hline
\end{tabular}

Abbreviations: BM, bilateral mastectomy; FH+, strong family history; FH -, no/minimal family history; Mut+, mutation positive; Mut-, no mutation detected. 
had a significant family history, but missed the concrete information afforded by a mutation-positive result. Two women struggled with this ambiguity.

\section{Unmet social support needs}

Table 4 shows quotations illustrating themes in relation to social support needs. FH+ Mut+ women appeared to experience the same social support deficits as those who were $\mathrm{FH}-$, as both struggled to come to terms with the emotional and practical implications of receiving Mut+ results. These included the practical issues of managing subsequent surgeries and long-term issues of finding a partner and having children.

It seemed that for both $\mathrm{FH}+$ and $\mathrm{FH}$ - women, having the support of someone who was their own age and going through similar experiences was very important. Coping with the implications of surgeries was a common theme for many women. For FH+ women, having only older relatives diagnosed with breast cancer did not seem to provide the social support required, as they did not face the same issues pertaining to a younger breast cancer diagnosis, such as inability to breastfeed or not having yet found a life partner. Social support deficits were also reported by $\mathrm{FH}+$ Mut - women. The uncertain meaning of this result and the same sentiment of older affected relatives being unable to offer support was mentioned.

Two women also mentioned trying to reach out through helplines, but still felt like they were unable to connect with the women due to differences in age and the impact of being mutation positive. Another woman instead found support in a group on Facebook with women who had been through similar experiences, and felt that this had in some way compensated for support deficits.

\section{Advantages of TGFT}

When women were asked to reflect on the advantages of TGFT, different patterns across the four groups of women emerged. For FH+ Mut+ women, the most commonly cited advantage was that the result eased the burden of treatment decisions. For FH - Mut+ women, the most commonly reported advantage was familial awareness, with every woman emphasising the impact this knowledge had on her family.
For one FH - Mut+ woman, the knowledge it provided her family led to the detection of several cancers, and for another numerous other relatives were found to carry the family-specific mutation. Another common advantage cited was in relation to treatment decisions, with one FH - Mut+ woman emphasising her peace of mind after deciding to have a BM. Women who received Mut - results more commonly mentioned the alleviation of worry, although mention was also made of easier treatment-related decisions because the need for a BM was removed.

\section{Disadvantages of TGFT}

Most women either said they were not aware of any disadvantages or listed disadvantages related to their carrier status, which was however qualified by an admission that it was better to know. One of the five $\mathrm{FH}$ - mutation carriers felt that the implications of genetic testing were not properly explained to her. She thought that for a younger woman the long-term impacts of knowing one's mutation status needed to be communicated in a more comprehensible way. Another $\mathrm{FH}+$ Mut - woman thought that the uncertainty that remained for women with a family history who had no mutation identified was a disadvantage.

\section{Suggestions for future TGFT}

Three women thought that a more formal follow-up by familial cancer clinics once the acute treatments phase was completed would have been good.

'There needs to be a follow up when a woman has finished her treatment to see what decisions they have made, do they have any extra questions etc. and just make sure that they are okay.' [33 years, FH+, Mut+, ID 4]

One woman suggested a group counselling session or method of connecting with other women facilitated through the genetic counsellors would have been useful.

\section{DISCUSSION}

To the best of our knowledge, this study is one of a small number of reports on the experiences of individuals with a low prevalence of

Table 4 Quotations illustrating themes in relation to social support and unmet needs

\begin{tabular}{|c|c|c|}
\hline & Women with a strong family history & Women with no/minimal family history \\
\hline Theme & Quotation illustrating theme & Theme and quotation illustrating theme \\
\hline Isolation & & Isolation \\
\hline
\end{tabular}

Lack of person of 'The big thing for me I think was the age difference, I think the way you 'I just found that every older women that I've spoken to, not many of them, similar age to identify with

they've just said, 'Oh well my boobs have served a purpose, I've breast-fed, they're saggy, I want them smaller anyway.' [33, FH - , Mut+, 5] 'The thing

\author{
The big thing for me I think was the age difference, I think the way you \\ view or deal with the disease, for me because I'm at a different part of, \\ stage of my life, I think my challenges were no, were not better or worse, \\ they were just different.' [38, FH+, Mut-, 10]
} I found hard is that I didn't have anyone to talk to about, like there was plenty of, like you could call up the Cancer Council and talk to other people that have had breast cancer, but I felt like there's nobody that's in my situation ... I just felt like I was you know forty years younger than everybody else that was there.' [28, FH - , Mut+]

Having the support 'My good friend was maybe two steps, you know two weeks ahead of me for 'It's good because you can bounce ideas of them ... So you know it's like of someone one's everything ... It was helpful for us to be able to just to talk to each other we get free counselling sort of thing.' [40, FH - , Mut-, a woman who own age and have someone else that knew' [40, FH+, Mut+, 15] found support through Facebook] 
familial cancer; ${ }^{11,17}$ the study extends the available literature by comparing the experiences of women with and without a strong family history of cancer in relation to TFGT. Findings demonstrate many qualitative differences in terms of women's adjustment to their diagnosis and their TFGT testing results depending on whether or not they had a pre-existing knowledge of a family cancer history. Women with a family history predominately described a sense of inevitability of their breast cancer diagnosis, whereas women without a family history typically reacted with shock and disbelief that they had a mutation. Women with a family history were able to refer to the experience of relatives for guidance about what to expect from breast cancer treatment and surgical decisions. These women appeared to frame their own prognosis in terms of positive or negative survivorship outcomes experienced by family members. In contrast, women without a family history lacked similar reference points for guidance about survivorship issues and surgical decisions and were more inclined to describe feelings of isolation and lack of support.

In terms of adjustment to a 'no mutation found' result, not surprisingly, women who were $\mathrm{FH}-$ described feelings of relief. In contrast, those who were $\mathrm{FH}+$ typically expressed surprise no mutation was found. Many of the FH+ Mut - women were aware that if a mutation was not detected in the context of a strong family history, the result was uninformative because there may still be an undetected mutation in $B R C A 1 / 2$ or a mutation in another cancer susceptibility gene. Accordingly many of these FH+ Mut - women were aware that their future breast cancer risk remained raised and struggled with ambiguity and uncertainty, as they still had difficult decisions to make without the clear guidelines available for risk management in the Mut+ group. These findings confirm results from previous studies, which report that with a personal diagnosis of cancer and a strong family history who underwent traditional testing and received an inconclusive result typically report frustration that they were unable to obtain a conclusive answer ${ }^{21}$ and distress over continuing uncertainty. ${ }^{22}$ Only one of the five FH+ Mut - women had BM, and we found that the women who had not elected BM reported a lack of closure following TFGT. It may be that FH+ Mutwomen who do not opt for $\mathrm{BM}$ at the time of diagnosis may require ongoing follow-up and genetic counselling to allow them to re-visit or adjust to their original decision against BM.

Regarding adjustment to a mutation-positive result, most carriers with a family history reported that they had expected to receive a Mut+ result, whereas $\mathrm{FH}-$ carriers typically described feelings of surprise and shock when they were informed they were carriers. FH+ Mut+ women seemed to appreciate the concrete answer provided by a positive mutation results; accordingly these women considered a positive mutation result straightforward in terms of its implications for surgery choice. In this subgroup, the ease of decision-making about $\mathrm{BM}$ was related back to their expectation of a Mut+ result and familiarity of mastectomy for breast cancer in other relatives. Indeed, some $\mathrm{FH}+$ carriers had already made a decision regarding BM before receipt of their result, and for these women the Mut+ result may have facilitated adjustment to BM.

In contrast, $\mathrm{FH}-$ women who received Mut+ results had more difficulties in making surgical decisions within a very short timeframe, which may be attributed to not having other relatives who serve as models regarding how risk management options might be implemented in practice. Compared with $\mathrm{FH}+$ mutation carriers, $\mathrm{FH}-$ women who received Mut+ results also reported more difficulties in adjusting psychologically to their mutation status and in sharing testing results with relatives. These findings are similar to those from studies on women with a diagnosis of breast cancer who underwent traditional testing; these studies show that those family members who are tested first are more prone to distress. ${ }^{23}$ and that women report that they found the disclosure of an inherited mutation particularly burdensome..$^{21}$

This study revealed many unmet social and professional support needs among carriers regardless of family history status, as well as in women with a family history who received a 'no mutation found' result. For carriers with and without a family history alike, having the support of someone who was their own age and going through similar experiences was considered important, underscoring results from a study of BRCA1/2 mutation carriers identified through traditional genetic testing, which showed that younger age and not having anyone to confide in were associated with higher unmet needs. ${ }^{24}$ Having difficulties in deciding about, and coping with the impact of, riskreducing surgeries was a common theme, underscoring findings from related studies demonstrating high levels of unmet information needs in this area. ${ }^{25,26}$

Before discussing the clinical implications of the findings, the limitations of the study should be mentioned. As with all qualitative studies, statistically valid generalisations cannot be undertaken, nor can causal relationships be established; however, we have also undertaken a quantitative comparison of women with and without a family history, the results of which will be reported separately. Also, this study was retrospective, which may have influenced participants' views, and there was also some variation in the length of time between the receipt of genetic test results and the qualitative interview. Although it may be of benefit to have sampled women at different times to capture adjustment processes, the small samples in each group mean that it is not possible to assess whether this variance was evenly distributed across subgroups. Finally, all participants in this study opted to receive their TFGT results, and it is therefore likely that participants self-selected for interest in genetic testing; future qualitative studies should seek to describe the view of women who are offered but decline TFGT.

\section{Clinical implications}

In this study we found that long-term adjustment to a mutationpositive result was hindered by a sense of isolation not only by those without a family history but also those with a family history who lacked an affected relative their age with whom they could identify. Mutation carriers may benefit from peer support programmes to meet their emotional and information needs. ${ }^{27-29}$ Women may also benefit from professional support through formal follow-up at the time of completion of active cancer treatment to provide additional support and information as needed.

\section{CONFLICT OF INTEREST}

The authors declare no conflict of interest.

\section{ACKNOWLEDGEMENTS}

We thank the patients who generously participated in this study. We also gratefully acknowledge the assistance of the surgeons and other staff who were involved at each site and who were integral to the success of this study. Thanks also to Mariana Souza for research assistance. We also acknowledge the support and endorsement of this project by the Psycho-oncology Cooperative Research Group (PoCoG).

\section{TFGT COLLABORATIVE GROUP}

The additional members of the Treatment Focused Genetic Testing Collaborative Group are in alphabetical order of group or institution:

P Gregory ${ }^{16}$, L Lipton ${ }^{16}$, L McKay ${ }^{16}$, J Senior ${ }^{16}$, L Lobb ${ }^{17}$, P Crowe ${ }^{18}$, A Matthews ${ }^{18}, \mathrm{G} \mathrm{Neil}^{18}$, A Parasyn ${ }^{18}$, D Thomson ${ }^{18}$, J Duffy ${ }^{19}, \mathrm{~L}_{\text {Andrews }}{ }^{19}$, 
J Gale $^{19}$, J Fox ${ }^{20}$, S Hart $^{20}$, C Smythe ${ }^{20}$, M White ${ }^{20}$, L Creighton ${ }^{21}$, J D'arcy ${ }^{21}$, S Grieve ${ }^{21}, \mathrm{E} \mathrm{Secomb}^{21}, \mathrm{M}$ Henderson $^{22}$, J O'Brien ${ }^{22}, \mathrm{C}^{2}$ Poliness $^{22}$, A Hattam ${ }^{23}$, R Susman ${ }^{23}$, O Ung ${ }^{23}$, R Dickson ${ }^{11}, \mathrm{~K}_{\text {Moore }}{ }^{11}, \mathrm{P}$ Bastick $^{24}$, S Inder ${ }^{24}$, $\mathrm{J} \mathrm{Lynch}^{24}$, P Schwartz ${ }^{24}, \mathrm{R} \mathrm{Zia}^{24}$, C Mak ${ }^{25}$, K Snook ${ }^{25}$, A Spillane ${ }^{25}$, J Hopper ${ }^{26}$,

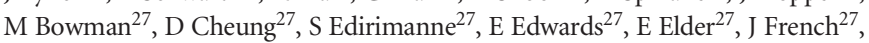
D Moon 27

${ }^{16}$ Cabrini HealthMelbourne, Australia; ${ }^{17}$ Calvary Centre for Palliative Care, Sydney, NSW, Australia; ${ }^{18}$ Department of Medical Oncology, Prince of Wales Hospital, Australia; ${ }^{19}$ Hereditary Cancer Clinic, Prince of Wales Hospital, Sydney, NSW, Australia; ${ }^{20}$ Monash Medical Centre, Melbourne, VIC, Australia; ${ }^{21}$ Nambour Hospital, Nambour, QLD, Australia; ${ }^{22}$ Peter MacCallum Cancer Centre, Melbourne, VIC, Australia; ${ }^{23}$ Royal Brisbane Hospital, Australia; ${ }^{24}$ St George Hospital, Sydney, NSW, Australia; ${ }^{25}$ The Poche Centre, Sydney, NSW, Australia; ${ }^{26}$ University of Melbourne, Australia; ${ }^{27}$ Westmead Hospital, Sydney, NSW, Australia

1 Robson M, Bradbury A, Arun B et al: American Society of Clinical Oncology policy statement update: genetic and genomic testing for cancer susceptibility. J Clin Oncol 2015; 33: 3660-3667.

2 National Breast and Ovarian Cancer Centre: Recommendations for Follow-up of Women with Early Breast Cancer. Surry Hills, NSW, Australia: National Breast and Ovarian Cancer Centre, 2010

3 Weitzel JN, McCaffrey SM, Nedelcu R, MacDonald DJ, Blazer KR, Cullinane CA: Effect of genetic cancer risk assessment on surgical decisions at breast cancer diagnosis. Arch Surg 2003; 138: 1323-1328.

4 Pierce LJ, Levin AM, Rebbeck TR et al: Ten-year multi-institutional results of breastconserving surgery and radiotherapy in BRCA1/2-associated stage I/II breast cancer [see comment]. J Clin Oncol 2006; 24: 2437-2443.

5 Fong P, Boss D, Yap T et al: Inhibition of poly(ADP-ribose) polymerase in tumors from BRCA mutation carriers. N Engl J Med 2009; 361: 1-12.

6 Byrski T, Huzarski T, Dent $\mathrm{R}$ et al: Pathologic complete response to neoadjuvant cisplatin in BRCA1-positive breast cancer patients. Breast Cancer Res Treat 2014, 147: 401-405.

7 Isakoff S, Mayer E, He L et al: TBCRC009: a multicenter phase II clinical trial of platinum monotherapy with biomarker assessment in metastatic triple-negative breast cancer. J Clin Oncol 2015; 33: 1902-1909.

8 Trainer A, Lewis C, Tucker K, Meiser B, Friedlander M, Ward R: Treatment-focused genetic assessment in breast cancer - the evolving role of the familial cancer services. Nat Rev Clin Oncol 2010; 7: 708-717.

9 Katz S, Kurian A, Morrow M: Decision-making and genetic testing for breast cancer. JAMA 2015; 314: 997-998.

10 Meiser B, Tucker K, Friedlander M et al: Genetic counselling and testing for inherited gene mutations in newly diagnosed patients with breast cancer: a review of the existing literature and a proposed research agenda. Breast Canc Res 2008; 10: 216.

11 Manchanda R, Loggenberg K, Sanderson S et al: Population testing for cance predisposing BRCA1/BRCA2 mutations in the Ashkenazi-Jewish community: a randomized controlled trial. J Natl Cancer Inst 2015; 107: 379.
12 King M, Levy-Lahad E, Lahad A: Population screening for breast cancer. JAMA 2014; 312: 1091-1092.

13 Hilgart J, Coles B, Iredale R: Cancer genetic risk assessment for individuals at risk of familial breast cancer. Cochrane Database Syst Rev 2012; 2; CD003721.

14 Hamilton JG, Lobel M, Moyer A: Emotional distress following genetic testing for hereditary breast and ovarian cancer: a meta-analytic review. Health Psychol 2009; 28 510-518

15 Schlich-Bakker KJ, Warlam-Rodenhuis CC, van Echtelt J, van den Bout J, Ausems MG, ten Kroode HF: Short term psychological distress in patients actively approached for genetic counselling after diagnosis of breast cancer. Eur J Cancer 2006; 42: 2722-2728.

16 Schlich-Bakker KJ, Ausems MG, Schipper M, Ten Kroode HF, Warlam-Rodenhuis CC: BRCA1/2 mutation testing in breast cancer patients: a prospective study of the longterm psychological impact of approach during adjuvant radiotherapy. Breast Cancer Res Treat 2008; 109: 507-514.

17 Shkedi-Rafid S, Gabai-Kapara E, Grinshpun-Cohen J, Levy-Lahad E: BRCA genetic testing of individuals from families with low prevalence of cancer: experiences of carriers and implications for population screening. Genet Med 2012; 14: 688-694.

18 Watts K, Meiser B, Mitchell G et al: How should we discuss genetic testing with women newly diagnosed with breast cancer? Design and implementation of a randomized controlled trial of two models of delivering education about treatment-focused genetic testing to younger women newly diagnosed with breast cancer. BMC Cancer 2012; 12 320.

19 Miles MB, Huberman AM, Saldana J: Qualitative Data Analysis: A Methods Sourcebook, 3rd edn. London: Sage, 2014.

20 Patton M: Qualitative Evaluation and Research Method, 3rd edn. London: Sage Publications, Inc., 2002.

21 Hallowell N, Foster C, Ardern-Jones A, Eeles R, Murday V, Watson M: Genetic testing for women previously diagnosed with breast/ovarian cancer: examining the impact of BRCA1 and BRCA2 mutation searching. Genet Test 2002; 6: 79-87.

22 Claes E, Evers-Kiebooms G, Boogaerts A, Decruyenaere M, Denayer L, Leguis E: Diagnostic genetic testing for hereditary breast and ovarian cancer in cancer patients: women looking back on the pre-test period and a psychological evaluation. Genet Test 2004; 8: 13-21.

23 Loader S, Shields CG, Rowley PT: Impact of genetic testing for breast-ovarian cancer susceptibility. Genet Test 2004; 8: 1-12.

24 Farrelly $\mathrm{A}$, White $\mathrm{V}$, Meiser $\mathrm{B}$ et al: Unmet support needs and distress among women with a BRCA1/2 mutation. Fam Cancer 2013; 12: 509-518.

25 Metcalfe K, Liede A, Hoodfar E, Scott A, Foulkes W, Narod S: An evaluation of needs of female BRCA1 and BRCA2 carriers undergoing genetic counselling. J Med Genet 2000; 37: 866-874.

26 Werner-Lin A: Formal and informal support needs of young women with BRCA mutations. J Psychosoc Oncol 2008; 26: 111-133.

27 Esplen MJ, Hunter J, Leszcz M et al: A multicenter study of supportive-expressive group therapy for women with BRCA1/BRCA2 mutations. Cancer 2004; 101: 2327-2340.

28 Landsbergen K, Brunner H, Manders $\mathrm{P}$ et al: Educational-support groups for BRCA mutation carriers satisfy need for information but do not affect emotional distress. Genet Couns 2010; 21: 423-437.

29 White V, Young M, Farrelly A et al: Randomized controlled trial of a Telephone-Based Peer-Support Program for women carrying a BRCA1 or BRCA2 mutation: impact on psychological distress. J Clin Oncol 2014; 32: 4073-4080. 